\title{
Ultra-Morphological Changes of Trichophyton Rubrum Treated with Hydroxychavicol
}

P. M. Ridzuan ${ }^{*}$, Nasir Mohamad ${ }^{b}$, Salwani Ismail ${ }^{a}$, Nor Iza A. Rahman ${ }^{a}$, Sanusi N.A ${ }^{a}$, Rabiatul Adawiyah Umar $^{\mathrm{a}}$, Hairul Aini Hamzah ${ }^{\mathrm{c}}$, Zunariah B. ${ }^{\mathrm{c}}$, M. H. Norazian ${ }^{\mathrm{d}}$, Baharudin Roesnita ${ }^{\mathrm{e}}$, aniversity of Sultan Zainal Abidin, Department of Preclinical, Faculty of Medicine, 20500 Kuala Terengganu, Terengganu, Malaysia

${ }^{b}$ University of Sultan Zainal Abidin, Department of Emergency and Trauma, Faculty of Medicine, 20500 Kuala Terengganu, Terengganu, Malaysia

'International Islamic University Malaysia, Department of Basic Medical Sciences, Kulliyyah of Medicine, 25200 Kuantan, Pahang, Malaysia

International Islamic University Malaysia, Department of Pharmaceutical Chemistry, Kulliyyah of Pharmacy, 25200 Kuantan, Pahang, Malaysia

${ }^{e}$ Hospital Tengku Ampuan Afzan, Department of Pathology, Microbiology Unit, 25100 Kuantan, Pahang, Malaysia

\begin{abstract}
Trichophyton rubrum is a common pathogenic fungal species that is responsible for causing infection on human skin, hair and nail. The antifungal-resistant strains complicate the treatment regime. Hydroxychavicol $(\mathrm{HC})$ is one of the main compounds from Piper betel leaf that have antifungal potential and its mechanism of action has not been studied yet. The objective of this preliminary study to determine the antifungal properties of $\mathrm{HC}$ against $T$. rubrum using transmission electron microscope (TEM) on gross and ultrastructure of $T$. rubrum hypha. $T$. rubrum was treated with $\mathrm{HC}$ and miconazole $(\mathrm{MI})$ at concentrations of $1.25,2.5,5$ and $10 \mathrm{mg} / \mathrm{mL}$ for $1,3,5$ and 7 days continuously. Generally, fungi structures became more severely damaged at increasing treatment duration. Microscopically, the fungi's cell wall treated with $\mathrm{HC}$ showed a rough surface, shrinkage and demolition similar to the Ml treated group. The fungi organelles were also demolished and disorganized. This study revealed that $\mathrm{HC}$ has the ability to inhibit $T$. rubrum growth and has potential to be an antifungal agent for skin infections.
\end{abstract}

Keywords: Piper betel, Trichophyton rubrum, hydroxychavicol, miconazole, antifungal.

\section{INTRODUCTION}

Trichophyton rubrum is a common pathogenic fungi that cause infection on human skin, hair and nails. This parasitic fungus has ability to invade the keratinized structure and also cause deeper infections such as kerions, abscesses and granulomas. ${ }^{1}$ Over pass several years, the number of fungal resistance to antifungal agents has dramatically increased every year. ${ }^{2}$ Thus, a new antifungal agent should be discovered to treat the infection caused by this pathogenic fungus. HC is one of the potential compounds that can be used as a new antifungal agent to treat $T$. rubrum infection.

$\mathrm{HC}$ is an active compound that can be found in Piper betel leave. ${ }^{3}$ This compound has been reported to be effective against several species of

Corresponding author:

Dr. P. M. Ridzuan

Deparment of Pre-Clinical

Faculty of Medicine

Universiti Sultan Zainal Abidin

Kuala Terengganu, Terengganu, Malaysia

Tel: 013-4748695

E-mail:ridzuan_pauzi@yahoo.com dermatophytes including T. rubrum. ${ }^{4} \mathrm{HC}$ were found to decrease the fungi growth and inhibit spore production. However, the effects on fungi morphology treated with $\mathrm{HC}$ are not well discribed. Thus, this preliminary study was conducted to know the ultramicroscopic effect of $\mathrm{HC}$ by using the Transmission Electron Microscopic (TEM) technique.

\section{MATERIALS AND METHODS}

\section{1) PREPARATION OF HC AND MI CONCENTRATION}

HC was purchased from FLUKA Analytical (USA) and prepared in methanol to make $10 \mathrm{mg} / \mathrm{mL}$ concentration. Four different concentrations $(10,5$, 2.5 , and $1.25 \mathrm{mg} / \mathrm{mL}$ ) of $\mathrm{HC}$ were prepared using two-fold dilution method with a slight modification. ${ }^{5}$ MI was used as a positive control in this study and was obtained from OXOID Ltd. (England). The same method was employed in Ml preparation with the same concentrations as $\mathrm{HC}$.

\section{2) PREPARATION OF T. rubrum}

The ATCC strain of $T$. rubrum (ATCC 28188) was purchased from MicroBiologics (France). The strain was cultured on Sabouraud dextrose agar (SDA) 
(OXOID Ltd., England) to grow the T. rubrum colony. Following Farzad et al. ${ }^{6}, T$. rubrum mycelia were harvested for electron microscopic examination and SDA was used to preserve the fungal mycelia from being exposed to high concentration of $\mathrm{HC}$ and $\mathrm{MI}$.

\section{3) SPECIMEN PREPARATION FOR TEM}

The same method were used to prepare both specimens to be treated with $\mathrm{HC}$ and Ml. One hundred and eighty (180) $\mu \mathrm{L}$ of fungi suspension was adjusted to 0.5 MacFarland containing between $1 \times$ $10^{4}$ to $1 \times 10^{5} \mathrm{CFU} / \mathrm{mL}$ colony was put into tubes and treated with $\mathrm{HC}$ and $\mathrm{Ml}(10,5,2.5$ and $1.25 \mathrm{mg} / \mathrm{mL})$ for $1,3,5$ and 7 days continuously. Based on the method performed by Farzad et al. ${ }^{6}$ and Park et al. ${ }^{7}$, the specimen for TEM observation was prepared with some modification. Fungi were cultured and treated with $\mathrm{HC}$ and MI. Then, samples were fixed with $2.5 \%$ gluteraldehyde at $4{ }^{\circ} \mathrm{C}$ for $15 \mathrm{~min}$. Fixed fungi were washed six times using distilled water. The samples were post-fixed with $2 \%$ osmium tetroxide at $4^{\circ} \mathrm{C}$ for $1 \mathrm{~h}$. The post-fixed samples were washed again for six times with distilled water and undergone dehydration process. The samples were dehydrated in a series of graded acetone concentrations from 70 to $90 \%$ (each for $10 \mathrm{~min}$ ) and finally dehydrated with $100 \%$ acetone for 15 min each for three times. The dehydrated samples were infiltrated with acetone. Then, the fungi were embedded with $100 \%$ resin and were kept overnight. After that, the fungi were polymerised in oven at $60^{\circ} \mathrm{C}$ for $24 \mathrm{~h}$. The next day, the samples were cut into ultrathin sections using ultra-microtome. The sectioned samples were then stained using Reynold staining for $10 \mathrm{~min}$ prior to examination under TEM. Untreated $T$. rubrum was used as the positive control.

\section{RESULTS}

Figure 1, 2, 3 and 4 showed the hypha of $T$. rubrum cultured on SDA medium. The horizontal section of untreated fungal hypha was used as a positive control to compare the morphological changes before and after the treatment with $\mathrm{HC}$ and MI. The cell wall, cell membrane and organelles of the fungus were clearly seen in the untreated fungal hypha.

Figure 1 displayed the $T$. rubrum hypha treated with $1.25 \mathrm{mg} / \mathrm{mL}$ of HC and MI. The fungal hypha showed morphological changes once exposed to the compounds. However, $\mathrm{HC}$ showed a better inhibition on fungi hypha than MI. At a low concentration, HC has already affected the fungal cell wall and organelles.

Conversely, figure 2 exhibited the $T$. rubrum hypha treated with $2.5 \mathrm{mg} / \mathrm{mL}$ of $\mathrm{HC}$ and MI. Fungi treated with $\mathrm{HC}$ displayed severe cytoplasm destruction and thickened cell wall. Besides, the cell membrane had also started to disintegrate from each other. In contrary, $T$. rubrum treated with $2.5 \mathrm{mg} / \mathrm{mL} \mathrm{MI}$ showed destruction of cytoplasm content and the cell membrane had started to detach itself from the cell wall when exposed to this drug.

However, fungi that were treated with $5 \mathrm{mg} / \mathrm{mL}$ of $\mathrm{HC}$ and $\mathrm{Ml}$ demonstrated a total disintegration and desolation of the cell wall and organelles when exposed to this concentration (figure 3). Figure 4 showed the $T$. rubrum hypha treated with $10 \mathrm{mg} /$ $\mathrm{mL}$ of $\mathrm{HC}$ and $\mathrm{Ml}$ whereby the $\mathrm{HC}$ destroyed the $T$. rubrum hypha through lysis. With this concentration the cell wall and compartment were totally damaged. At the same concentration of Ml, the cytoplasmic compartment also showed desolation and disintegration. Generally, this concentration causes severe damage to cell wall and organelles.

\section{DISCUSSION}

This study found that $\mathrm{HC}$ was effective in inhibiting $T$. rubrum hypha by disrupting the cell wall rigidity and damaging the fungal organelles. In addition, this study showed that $\mathrm{HC}$ can be a good antifungal because it has the ability to affect the growth of hypha at a low concentration $(1.25 \mathrm{mg} / \mathrm{mL})$. Higher concentrations of $\mathrm{HC}$ (i.e., 5 and $10 \mathrm{mg} / \mathrm{mL}$ ) are more effective in inhibiting the fungal hypha compared to the lower concentrations tested (i.e., 1.25 and $2.5 \mathrm{mg} / \mathrm{mL}$ ). Furthermore, the effect of $\mathrm{MI}$ on fungi shows a similar effect with $\mathrm{HC}$ at the same concentration. This could be due to the purity of $\mathrm{HC}$ compound $(95 \%)$ purchased from the supplier compared to the one isolated from $P$. betel leave extract using High-Performance Liquid Chromatography (HPLC). Improper procedure of compound preparation might pose higher possibility of contamination. The impure $\mathrm{HC}$ could not reflect the actual effect of the compound. Hence, in this study, the HC was purchased instead of being prepared manually.

Based on the observation from the TEM images, HC was found able to inhibit $T$. rubrum hypha by damaging the fungal cell wall, separating the cell membrane and disorganising the cytoplasmic components. The study by Farzad et al. ${ }^{6}$ found that garlic extract containing allicin inhibited the growth of $T$. rubrum hypha through shrinking and flattening of the cell and through cell wall demolition. The same action of fungal destruction might be possessed by HC. Thus, this finding gives better understanding regarding the effects of $H C$ on $T$. rubrum hypha.

Research on antifungal substance against the dermatophyte fungus increases steadily every year. One of the researches that aimed to discover new antifungal drug using Paenibacillus kribbensis POC 115 against the dermatophyte $T$. rubrum was done by Cotta et al. ${ }^{1}$. In this study, P. kribbensis was selected and cultured before it was purified to identify the antimicrobial effects using Ultra Performance Liquid Chromatography (UPLC). From the result, two compound peaks were observed and 
they were correlated to the iturin family group based on a set primer that was designed for the amplification of POC 115 genome. Antimicrobial substance (AMS) produced by POC 115 caused the disruption of cytoplasmic membrane of $T$. rubrum and it appeared to be a good potential antifungal for dermatophyte especially against $T$. rubrum species.

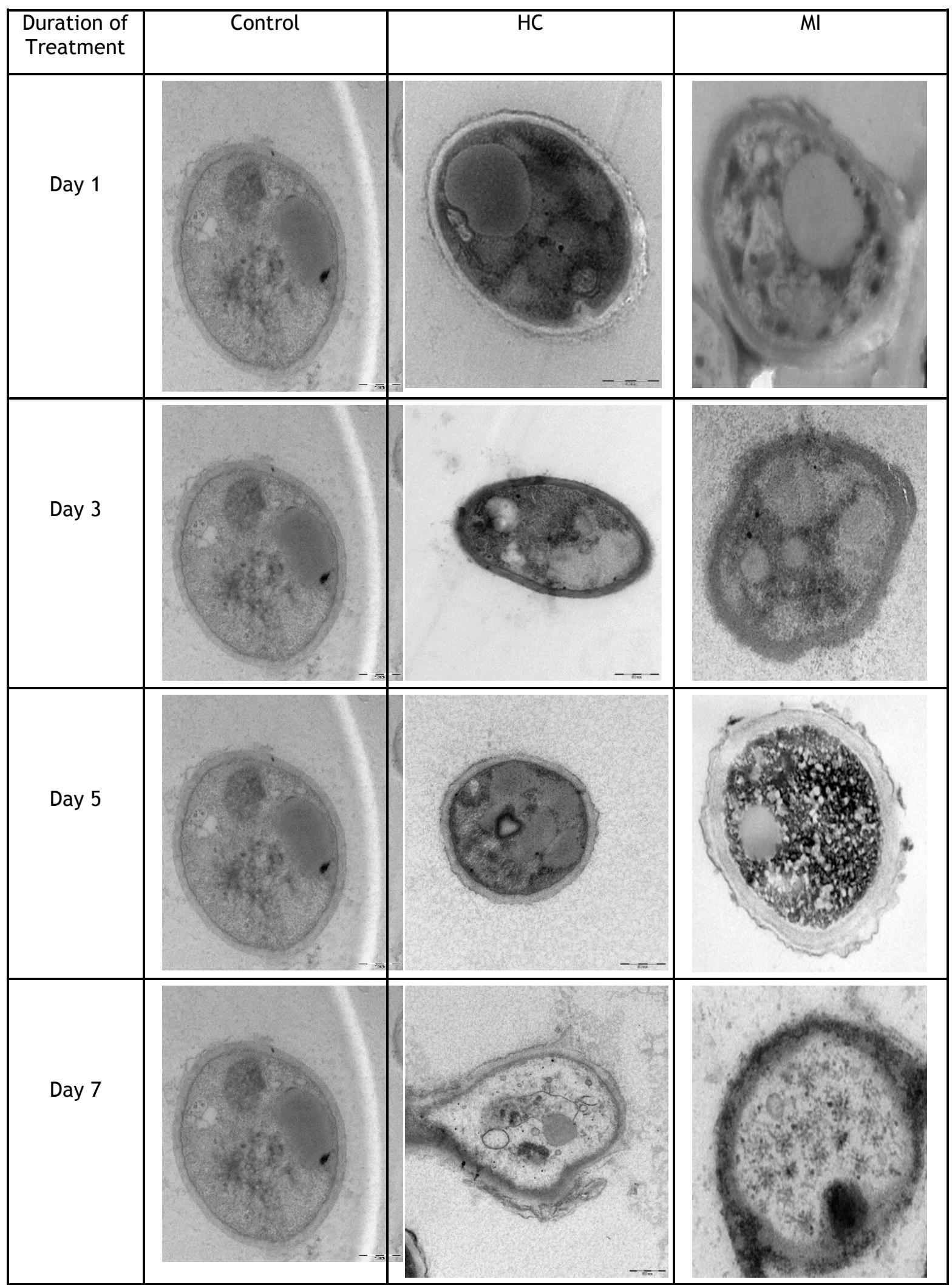

Figure 1: TEM images of $T$. rubrum hypha section treated with $1.25 \mathrm{mg} / \mathrm{mL}$ of $\mathrm{HC}$ and $\mathrm{Ml}$ at different duration of treatment. 


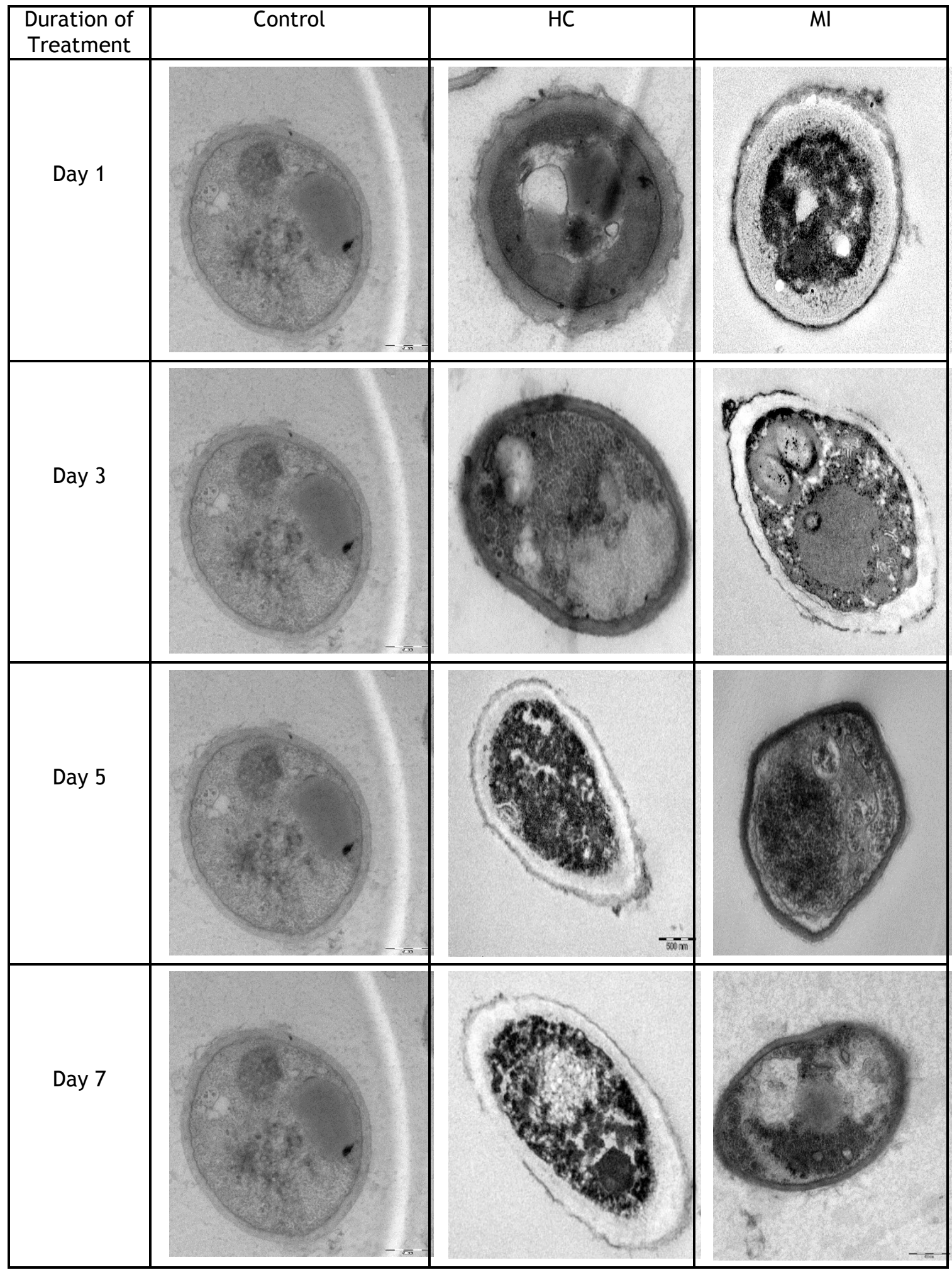

Figure 2: TEM images of $T$. rubrum hypha section treated with $2.5 \mathrm{mg} / \mathrm{mL}$ of $\mathrm{HC}$ and $\mathrm{Ml}$ at different duration of treatment. 


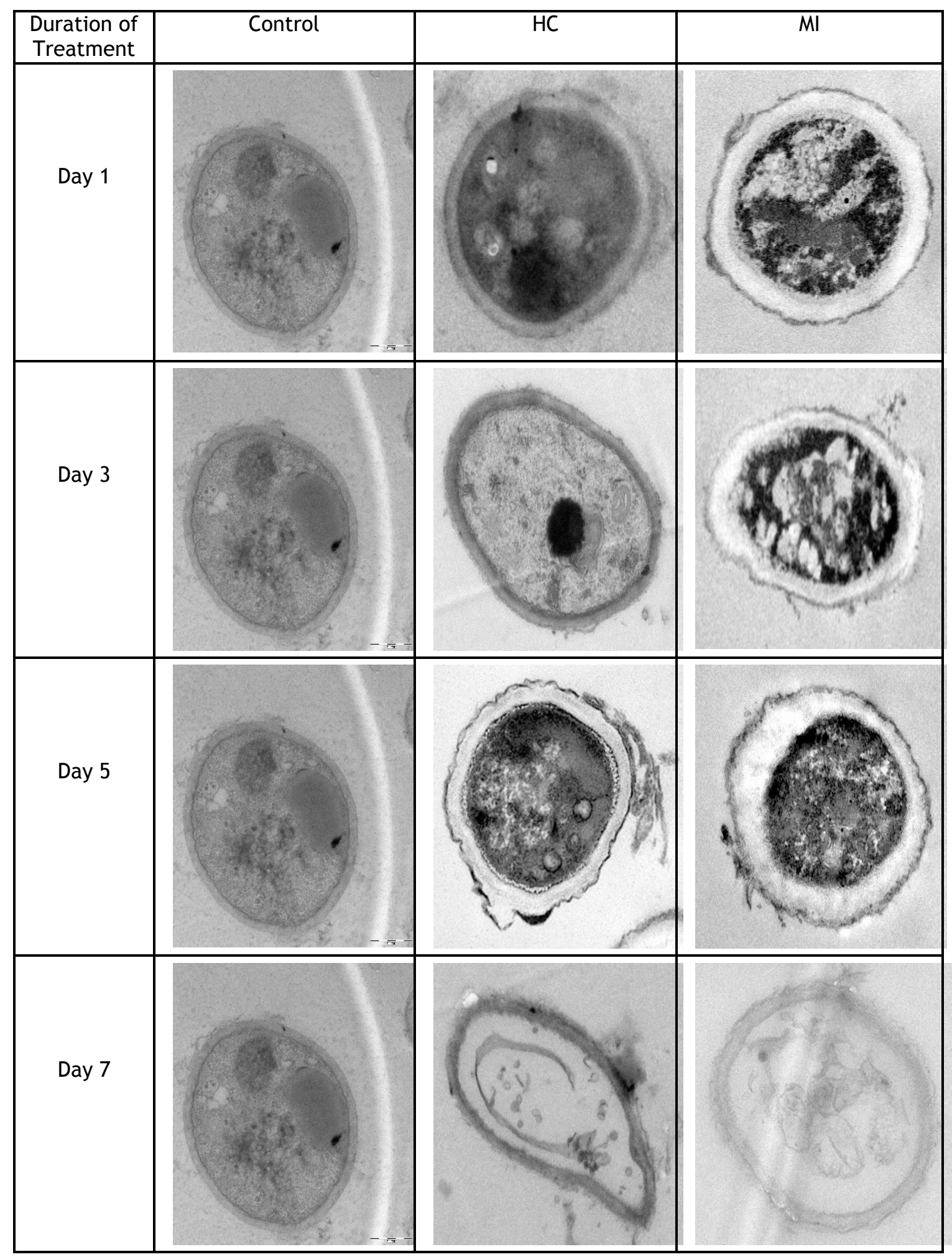

Figure 3: TEM images of $T$. rubrum hypha section treated with $5 \mathrm{mg} / \mathrm{mL}$ of $\mathrm{HC}$ and $\mathrm{Ml}$ at different duration of treatment. 


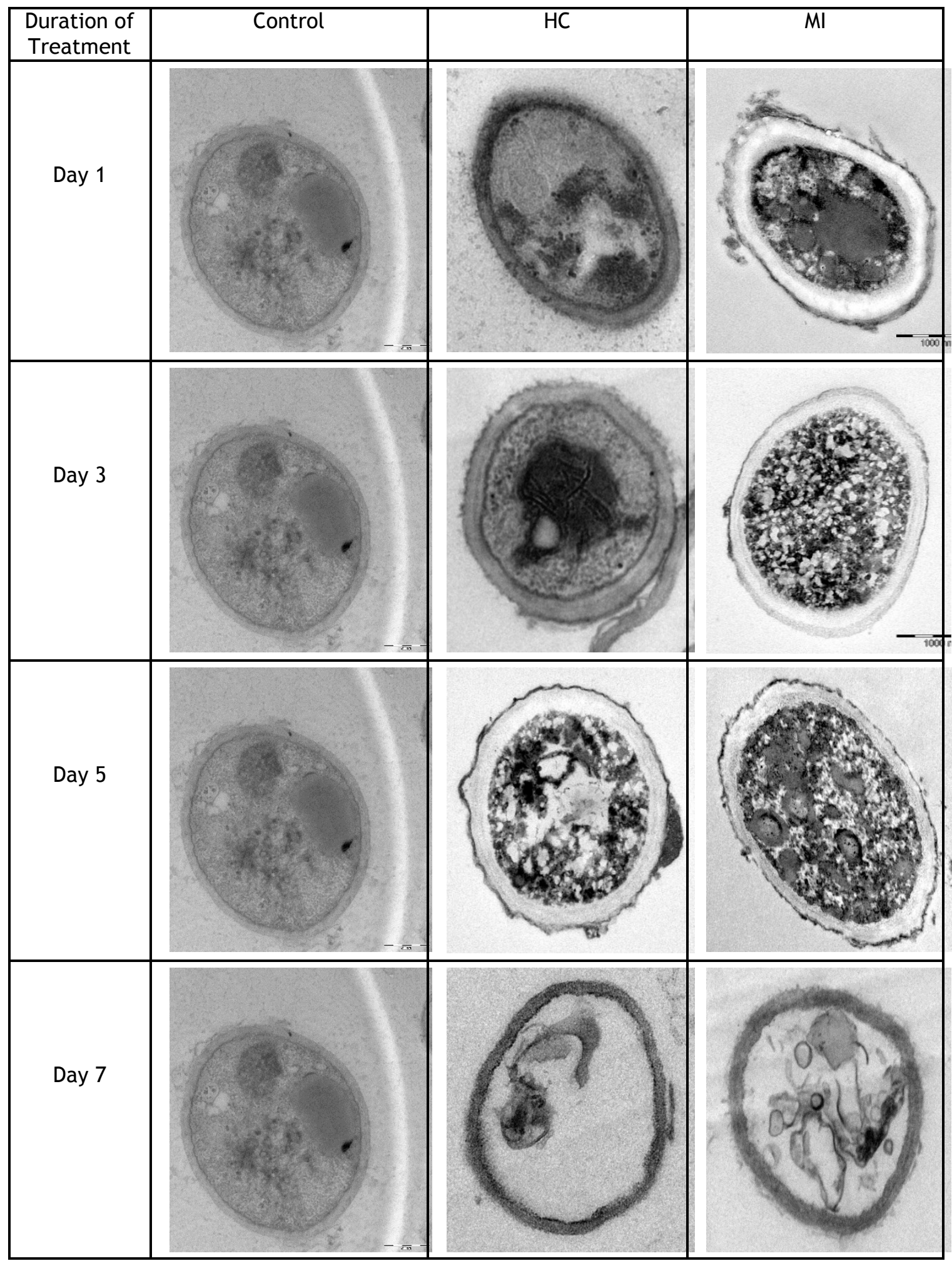

Figure 4: TEM images of $T$. rubrum hypha section treated with $10 \mathrm{mg} / \mathrm{mL}$ of $\mathrm{HC}$ and $\mathrm{Ml}$ at different duration of treatment.

\section{CONCLUSION}

This research showed $\mathrm{HC}$ possess a good antifungal effect against $T$. rubrum similar to that with MI. It proofs that $\mathrm{HC}$ able to use as an antifungal agent for treating $T$. rubrum skin infection in the future.

\section{ACKNOWLEDGEMENT}

The authors would like to thank Ministry of Education Malaysia for the research grant support through Fundamental Research Grant Scheme (FRGS/2/2014/SKK04/UNISZA/02/1), Faculty of Medicine of University Sultan Zainal Abidin (UniSZA), Kulliyyah of Medicine and Kulliyyah of Pharmacy of International Islamic University Malaysia (IIUM), Department of Pathology of Hospital Tengku Ampuan Afzan (HTAA), Mr. Santhana Raj from Institute for Medical Research (IMR) and Hospital Sultanah Nur Zahirah (HSNZ). 


\section{REFERENCES}

1. Cotta, S. R., Mota, F. F. d., Tupinamba, G., Ishida, K., Rozental, S., \& Silva, D. O. E., 2012. Antimicrobial Activity of Paenibacillus kribbensis POC 115 against the dermatophyte Trichophyton rubrum. World J Microbiol Biotechnol, 28: 953962.

2. Adhikari, R. P., Cook, G. M., Lamont I., Lang, S., Heffernan H., \& Smith John M. B. (2002). Phenotypic and molecular characterization of community occurring, Western Samoan phage pattern methicillin-resistant Staphylococcus aureus. Journal of Antimicrobial Chemotherapy, 50, 825-831.

3. Chang, M., Uang, B., Tsai, C., HLWu, Lin, B., \& Lee, C., 2007. Hydroxychavicol, a Novel Betel Leaf Component, Inhibits Platelet Aggregation by Suppression of Cyclooxygenase, Thromboxane Production and Calcium Mobilisation. British Journal of Pharmacology, 152: 73-82.

4. Ali, I., Khan, F. G., Suri, K. A., Gupta, B. D., Satti, N. K., \& Dutt, P. (2010). In vitro antifungal activity of hydroxychavicol isolated from Piper betle L. Annals of Clinical Microbiology and Antimicrobials, 9(7), 1-9.

5. P.M.Ridzuan, H. Hairul Aini, M. H. Norazian, A. Shah, Roesnita,K. S. Aminah., 2013. Antibacterial and Antifungal Properties of persicaria odorata Leaf Against Pathogenic Bacteria and Fungi. The Open Conference Proceedings Journal,4: 71-74.

6. Farzad Aala, Umi Kalsom \& Rosimah Nulit., 2013. Electron Microscopy Studies of the Effects of Garlic Extract Against Trichophyton rubrum. Sains Malaysiana, 42(11): 1585-1590.

7. Park,M.J., Gwak, K.S., Yang, I., Kim, K.W., Jeung, E.B. \& Chang, J.W., 2009. Effect of cital, eugenol, nerolidol and á-terpineol on the ultrastructural changes of Trichophyton mentagrophytes. Fitoterapia, 80: 290-296.Spicer, W. J., 2008. Clinical Microbiology And Infectious Diseases (2nd ed.): Churhill Livingstone Elsevier. 